\title{
Pilon kırıklarında radyolojik değerlendirme ve sınıflama
}

\author{
Radiologic evaluation and classification of pilon fractures
}

\author{
Engin Çetin, Ufuk Özkaya \\ Gaziosmanpaşa Taksim Eğitim ve Araştırma Hastanesi, Ortopedi ve Travmatoloji Bölümü, İstanbul
}

Tibia pilon kırıkları, genellikle yüksek enerjili travmalar ile oluşan ve tedavisi güç kırıklardır. Başarı, hastanın sistematik bir yaklaşımla iyi ele alınmasına, kırık özelliklerinin ve yumuşak dokunun durumunun doğru değerlendirilmesine bağlıdır. Bilgisayarlı tomografi (BT) incelemesi, rutin grafileri takiben, eklemdeki yer değiştirmeyi, kırık fragmanlarının yerleşimini tespit etmek ve bu bilgiler ışında tedaviyi planlamak için yapılması zorunlu bir tetkiktir. Pilon kırıkları, yaygın olarak direkt grafileri temel alan Rüedi ve Allgöwer, ve $A O$ Foundation and Othopaedic Trauma Association (AO/ OTA) sınıflamaları ile sınıflandırılırken; BT temelli tedaviyi yönlendiren sınıflamalar da tanımlanmıştır.

Anahtar sözcükler: pilon kırıkları; plafond kırıkları; distal tibia; sınıflandırma
Tibia pilon fractures are usually the result of high-energy traumas and their management is challenging for surgeons. Success of the treatment depends on meticulous and systematic evaluation of the fracture characteristics and condition of the soft tissue envelope. Computerized tomography (CT) examination following routine $X$-ray is mandatory to define the joint displacement and location of bone fragments. Pilon fractures are usually evaluated by Rüedi and Allgöwer, and AO Foundation and Othopaedic Trauma Association (AO/OTA) classifications that are based on $\mathrm{X}$-ray examinations. Besides, CT based classifications are also defined which contribute to management decisions.

Key words: pilon fractures; plafond fractures; distal tibia; classification

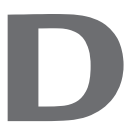
istal tibianın, epifiz-diafiz devamlılığının bozulduğu eklem kırıkları pilon kırıkları olarak adlandırılır. illk kez 1911 yılında, Fransız radyolog Destot tarafindan kullanılan pilon terimi, havaneli manasına gelen Fransızca bir kelimedir. Yüksekten düşme veya motorlu taşıt kazaları gibi yüksek enerjili travmaların meydana getirdiği aksiyel kuvvetler, talusun distal tibia içine doğru hareketine ve tibia eklem yüzü ile metafizinin parçalanmasına neden olur. ${ }^{[1]}$

Aksiyel yüklenmeler en sık görülen yaralanma mekanizması olmasına rağmen, rotasyon yaralanmalarıyla da pilon kırıkları meydana gelebilir. Travmanın şiddetine ve kuvvetin yönüne göre farklı problemlerin görüldüğü üç farklı hasta grubu tanımlanmıştır. illk grupta yüksek enerjili travmalara maruz kalan hastalar bulunur. Şiddetli travma, kemikte parçalanma, impaksiyon ve yer değiştirmeye neden olurken, bu bölgedeki ince yumuşak doku örtüsüne de ciddi hasar verir. Fibula genellikle kırılmıştır. Açık kırıkların ve sekonder cilt nekrozunun görülme ihtimali bu grupta fazladır. İkinci grupta daha düşük enerjili, kayak kazalarında olduğu gibi rotasyon yaralanmalarına maruz kalan hastalar bulunur. Bu hastalarda kıkırdak impaksiyonunun görülmediği, spiral şekilli pilon kırıkları görülmektedir. Fibula genellikle sağlamdır. Üçüncü grubu ise, yaşlı osteoporotik hastalar oluşturur. Bu hastalarda minör travmalar ile parçalanmanın nispeten daha sınırlı olduğu pilon kırıkları görülür (Şekil 1). ${ }^{[2]}$

Travma sırasında ayağın pozisyonu da, meydana gelen kırığın özelliklerini belirleyen önemli bir faktördür. Tipik olarak, aksiyel kuvvetler, ayak plantar fleksiyondayken posterior eklem yüzeyinin parçalanmasına, dorsifleksiyondayken anterior eklem yüzeyinin parçalanmasına, nötral poziyondayken ise tüm eklem yüzeyinin parçalanmasına neden olur.

Pilon kırıklarının radyolojik değerlendirmesi direkt grafiler ile başlar. Ayak bileği ön-arka (AP), mortis ve lateral grafileri cerraha kırık özellikleri hakkında fikir verir. Tüm tibia grafisi, röntgen ışınları diafiz üzerine

- Illetişim adresi: Uzman Dr. Engin Çetin, Gaziosmanpaşa Taksim Eğitim ve Araştırma Hastanesi, Ortopedi ve Travmatoloji Bölümü, İstanbul Tel: 0532 - 4101329 e-posta: enginctn@yahoo.com.tr

- Geliş tarihi: 3 Mayıs $2016 \quad$ Kabul tarihi: 3 Mayıs 2016 

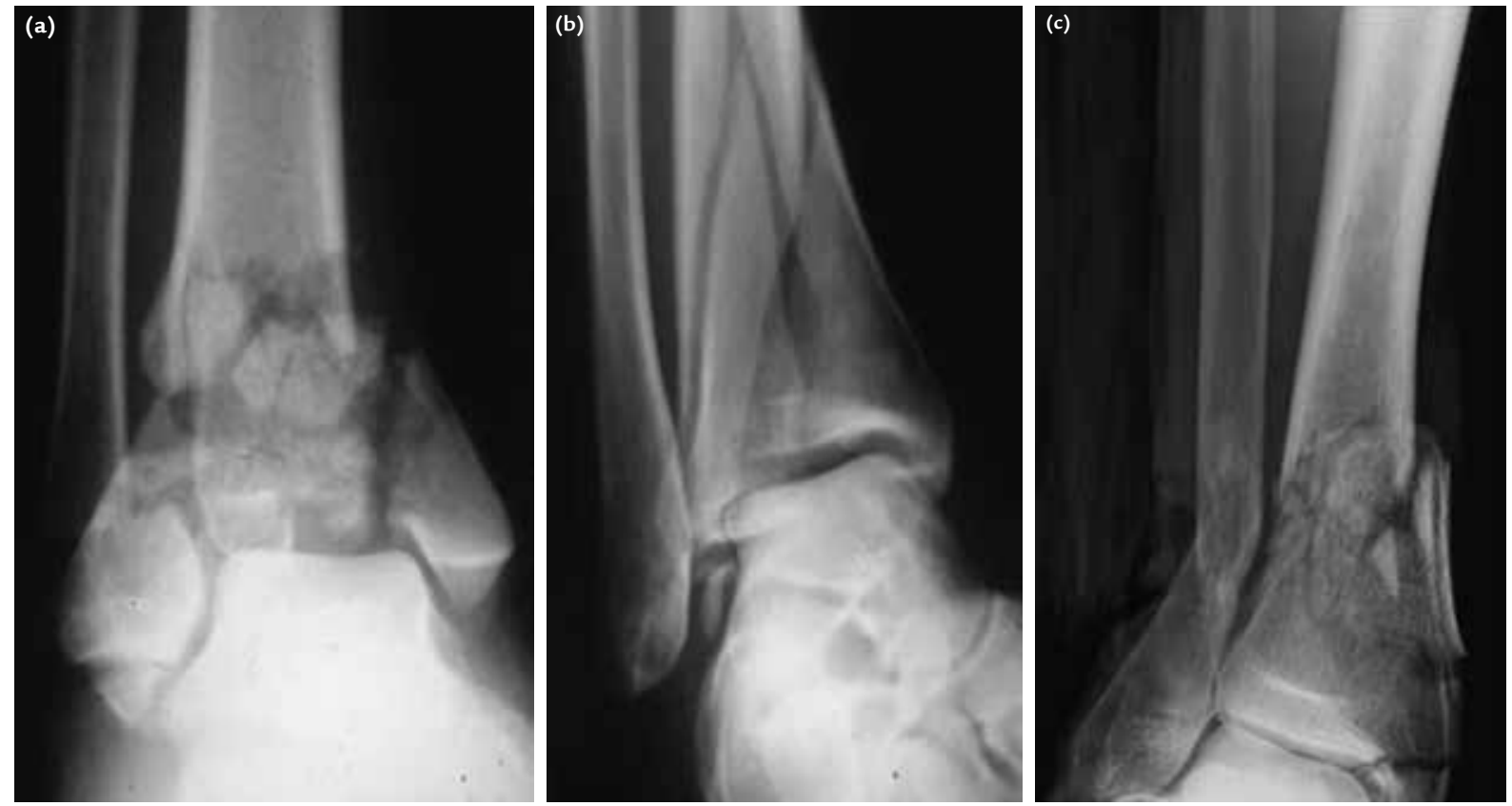

Şekil 1. a-c. Yüksek enerjili aksiyel kompresyon kırığı (a); rotasyonel yaralanma (b); osteoporotik kemikte genellikle metafizi ilgilendiren impaksiyon kırığı (c).

odaklandığı için, pilon kırıklarının değerlendirilmesinde uygun değildir. Aynı taraftaki diz eklemi ve ayak, eşlik edebilecek kırıkların tespit edilebilmesi amacıyla mutlaka görüntülenmelidir. Kırık yüksekten düşme sonrasında meydana gelmişse, hastada spinal yaralanma ile ilgili bulgular ve semptomlar varsa veya hastanın şuuru kapalı ise, lumbosakral omurga da değerlendirmeye dahil edilmelidir. Karşı taraf ayak bileğinin değerlendirilmesi, cerrahi öncesi planlamada bir şablon oluşması açısından yararlı olabilir; bu aynı zamanda eşlik eden, daha az semptomatik kırıkların tespitinde de yararlıdır. ${ }^{[3]}$

Bilgisayarlı tomografi (BT), kırık fragmanlarının sayısını, yerleşimini, yer değiştirmeyi ve eklem kıkırdağındaki çökmeyi daha iyi göstermesi açısından yararlı bir tetkiktir. Nihai tedavinin planlanması aşamasında mutlaka değerlendirilmelidir. îlk değerlendirmeden ziyade, geçici eksternal fiksatör uygulamasını takiben yapılması önerilmektedir. Pilon seviyesinde aksiyel kesitler kırık oryantasyonunu gösterirken, sagittal ve koronal rekonstrüksiyonlar tüm kırık morfolojisinin değerlendirilmesine olanak sağlar. ${ }^{[4]}$ Tornetta ve arkadaşları, pilon kırığı olan 22 hastalarının \%64'ünde, BT görüntüleme sonrasında cerrahi yaklaşımlarını değiştirdiklerini bildirmişlerdir. Ana kırık çizgisinin medialde olduğu olgularda anteromedial yaklaşımı, lateralde olduğu olgularda ise lateral yaklaşımı kullanarak cerrahi girişim gerçekleştirmişlerdir. ${ }^{[5]}$

Pilon kırıklarında, tipik olarak üç ana kırık fragmanı görülmektedir. Bunlar;
- Anterior tibiofibular bağın yapıştığı anterolateral fragman (Chaput fragmanı)

- Posterior tibiofibular bağın yapıştığı posterior fragman (Volkmann fragmanı) ve

- Medial kollateral bağın yapıştığı medial fragmandır (Şekil 2).

Bu fragmanlar farklı büyüklüklerde, kimi olgularda parçalanmış, zaman zaman da tibia distal diafizi fragmanların arasına girmiş olabilir. ${ }^{[2]}$

Pilon kırıkları için, direkt grafi görüntülerini temel alan ve yaygın olarak kullanılan iki temel sınıflandırma sistemi mevcuttur. Bunlar Rüedi ve Allgöwer ${ }^{[6]}$ ve AO Foundation and Orthopaedic Trauma Association (AO/ OTA) sınıflamalarıdır. ${ }^{[7]}$

Rüedi ve Allgöwer, eklem fragmanlarının boyutuna ve yer değiştirmesine göre üç farklı pilon kırı̆̆ı tipi tanımlamışlardır. Bunlar;

- Tip 1: Eklem uyumunun bozulmadığı, basit metafizyel ve eklem kırkları,

- Tip 2: Eklemde yer değiştirmenin olduğu, az parçalı kırıklar ve

- Tip 3: Eklemde yer değiştirmenin olduğu, çok parçalı kırıklardır (Şekil 3).

Kırı̆̆ın ciddiyetini tanımlayan, nispeten uygulaması kolay olan bu sınıflama sisteminin değerlendiriciler arası güvenilirliği zayıf bulunmuştur. ${ }^{[8]}$ 


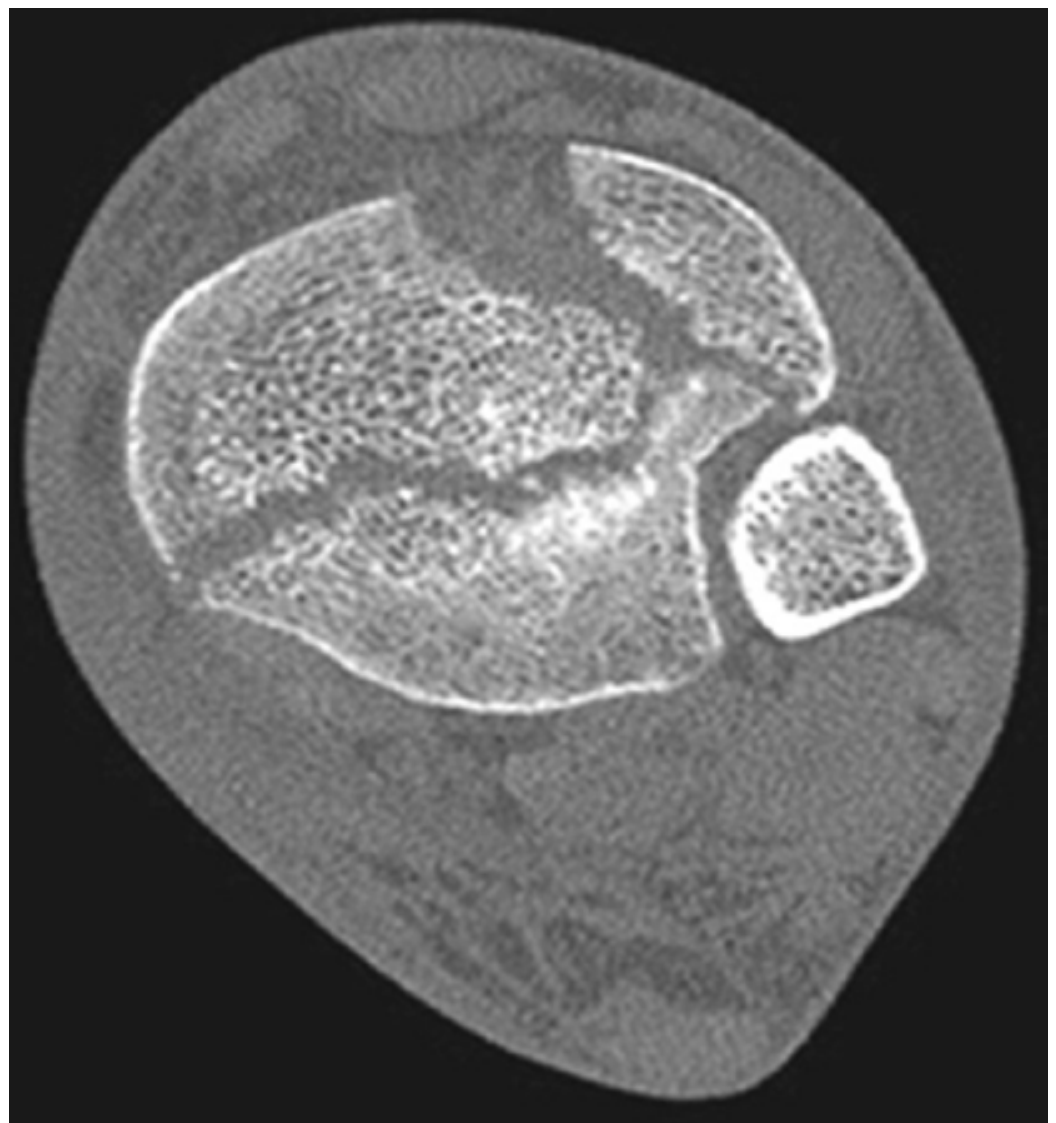

Şekil 2. Üç ana kırk fragmanını gösteren BT kesiti.

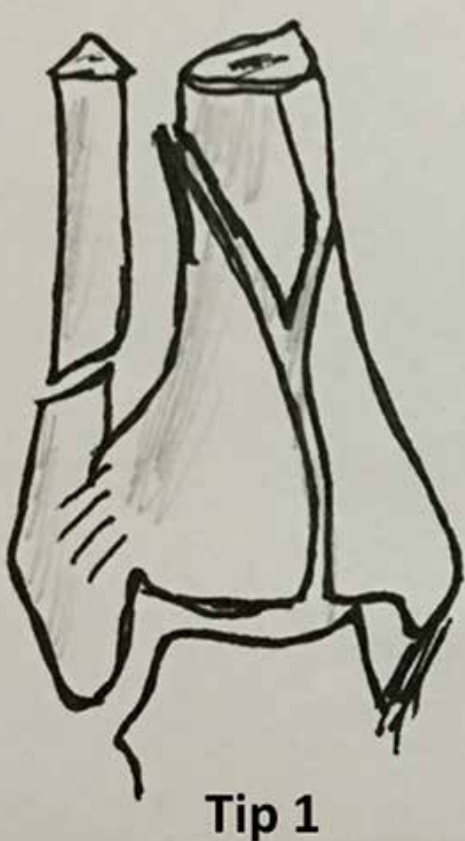

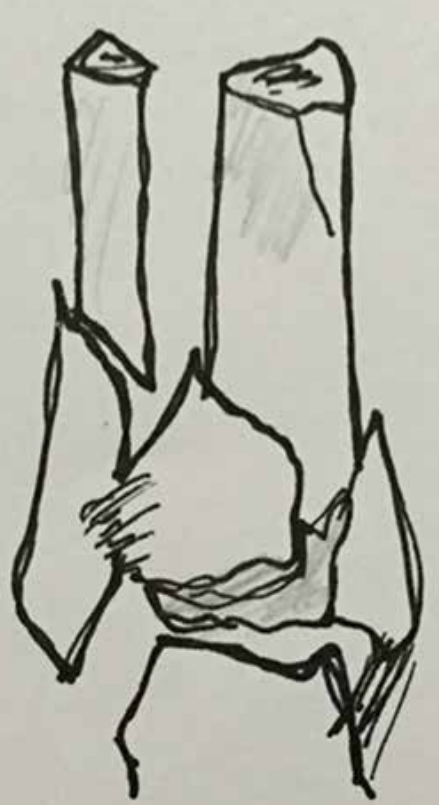

Tip 2

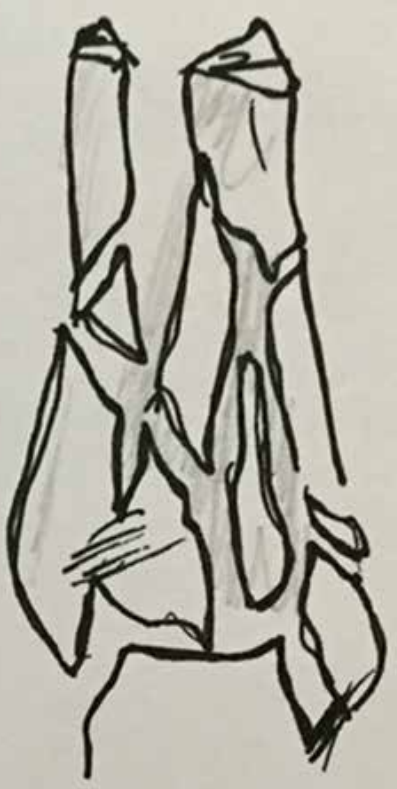

Tip 3

Şekil 3. Rüedi ve Allgöwer sınıflaması. Tip 1, eklem uyumunun bozulmadığı, basit metafizyel ve eklem kırkları; Tip 2, eklemde yer değiştirmenin olduğu, az parçalı kırıklar; Tip 3, eklemde yer değiştirmenin olduğu, çok parçalı kırıklardır. 


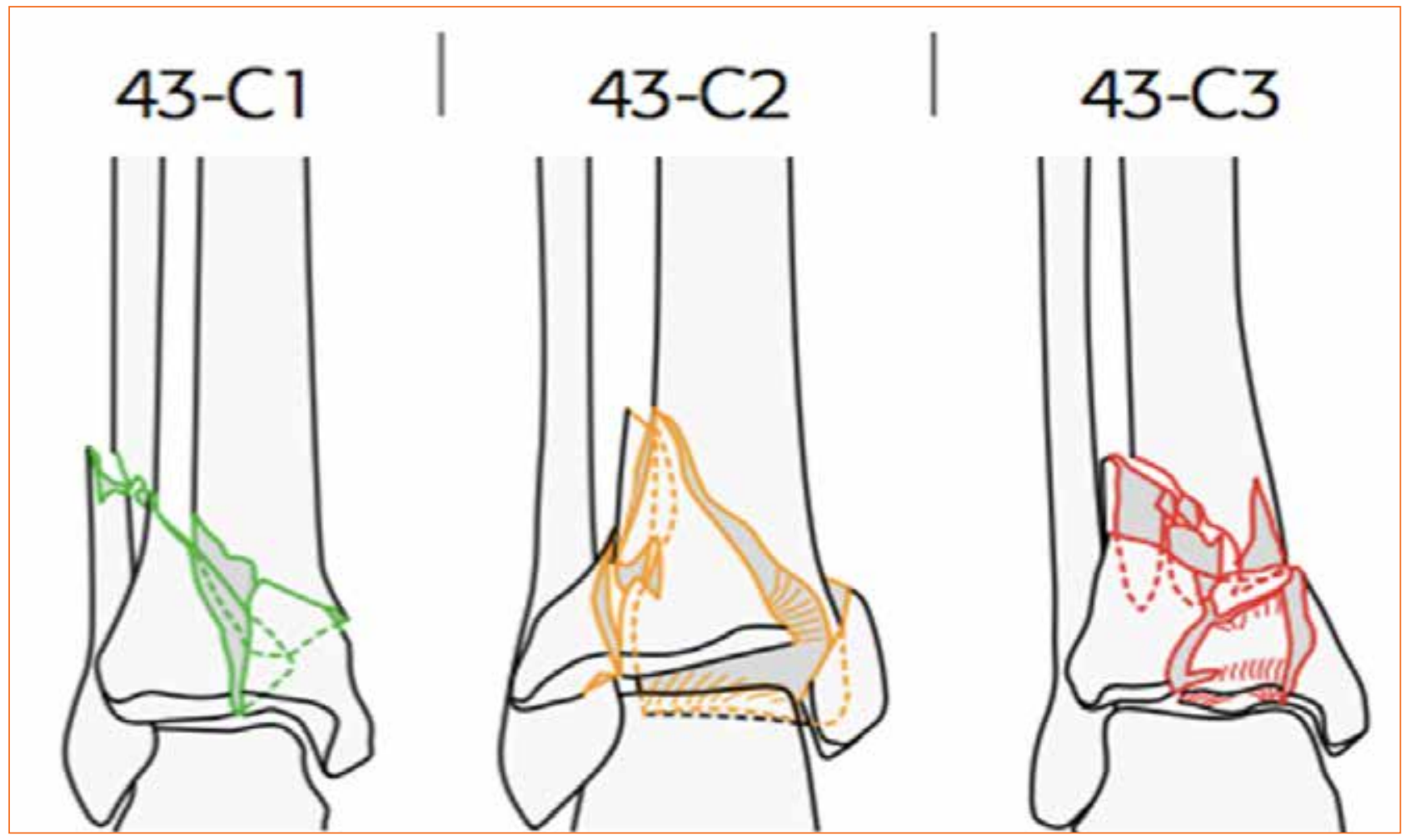

Şekil 4. AO/OTA sınıflaması: 43, distal tibia eklem kırıkları; 43-C1, eklem basit, metafizyel basit; 43-C2, eklem basit, metafiz çok parçalı; 43-C3, çok parçalı eklem kırığı. (Referans: AOTrauma AO/OTA Fracture and Dislocation Classification leaflet)

AO/OTA sınıflaması, kırık tiplerini alfanumerik bir sistem ile tanımlamaktadır. Burada ilk rakam kemiği, ikinci rakam ise kemik segmentini belirtir ki, bu distal tibia için " 43 "tür. Bu rakamları takiben " $A$ " ayak bileği eklemine $5 \mathrm{~cm}$ mesafedeki eklem dışı kırıkları, "B" kısmi eklem içi kırıkları tanımlamaktadır; pilon kırıkları bu gruplar içinde yer almaz. "C" ise, diafiz ve eklem devamlılığının tamamen bozulduğu eklem içi kırıklarını ifade etmektedir. Bu grup, pilon kırıklarının büyük çoğunluğunu kapsamaktadır. Bu sınıflamadaki son rakamlar ise her tipteki alt grupları tanımlamak için kullanır; eklemin ve metafizin parçalanma derecesini ifade eder. Pilon kırıkları için, C1: basit bir eklem kırığına eşlik eden basit bir metafiz kırığını, C2: basit bir eklem kırığına eşlik eden parçalı bir metafız kırığını, C3: eklem ve metafizin çok parçalı olduğu kırık tipini ifade etmektedir (Şekil 4). Swiontkowski ve arkadaşları, AO/OTA sınıflamasının, değerlendiriciler arası güvenilirliğini $A$, $B$ ve $C$ gruplarını tanımlarken orta derecede, alt grup tanımlamasında zayıf olarak bulmuşlardır. Ayrıca, kırığın alt gruplara ayrılarak tanımlanmasını sağlıklı bulmamışlardır. ${ }^{[9]}$ Yine başka bir çalışmada, AO/OTA sınıflamasının değerlendiriciler arası güvenilirliğinin, kırık tipini belirlerken yüksek, fakat alt grup seviyesinde zayıf olduğu bildirilmiş; genel olarak güvenilirliğinin ise Rüedi ve Allgöwer sınıflamasından daha iyi olduğu belirtilmiştir. ${ }^{[8]}$

Pilon kırıklarının radyolojik değerlendirmesinde dikkat edilmesi gereken çok önemli bir konu da, tibianın hangi yönde deformasyon gösterdiğidir. Tibianın varus veya valgus yönünde deforme olması, cerrahi yaklaşımı ve kullanılacak stabilizasyon materyalinin seçimini etkileyen önemli bir faktördür. Varus deformasyonu olan bir pilon kırığı en iyi medial destek pla$\breve{g}_{\text {ı }}$ ile tespit edilebilirken, valgus deformasyonu olan bir kırık, anterolateral plak iyi daha iyi tespit edilebilir (Şekil 5). ${ }^{[10]}$

Direkt grafileri temel alan sınıflamaların yanında, aksiyel BT görüntülerini temel alan ve tedaviyi yönlendiren sınıflamalar da tanımlanmıştır. Topliss ve arkadaşları, pilon kırıklarını BT görüntülerine göre değerlendirmişler, aksiyel kesitteki kırık çizgisinin yönüne göre, kırıkları sagittal ve koronal olarak sınıflamışlardır. Sagittal plan kırıklarının, varus deformasyonu ile birlikte, gençlerde ve daha yüksek enerjili yaralanmalar ile meydana geldiğini; koronal plan kırıklarının ise valgus deformasyonu ile birlikte, daha ileri yaşlardaki hastalarda, daha düşük enerjili yaralanmalar ile meydana geldiğini bildirmişlerdir. ${ }^{[11]}$ 

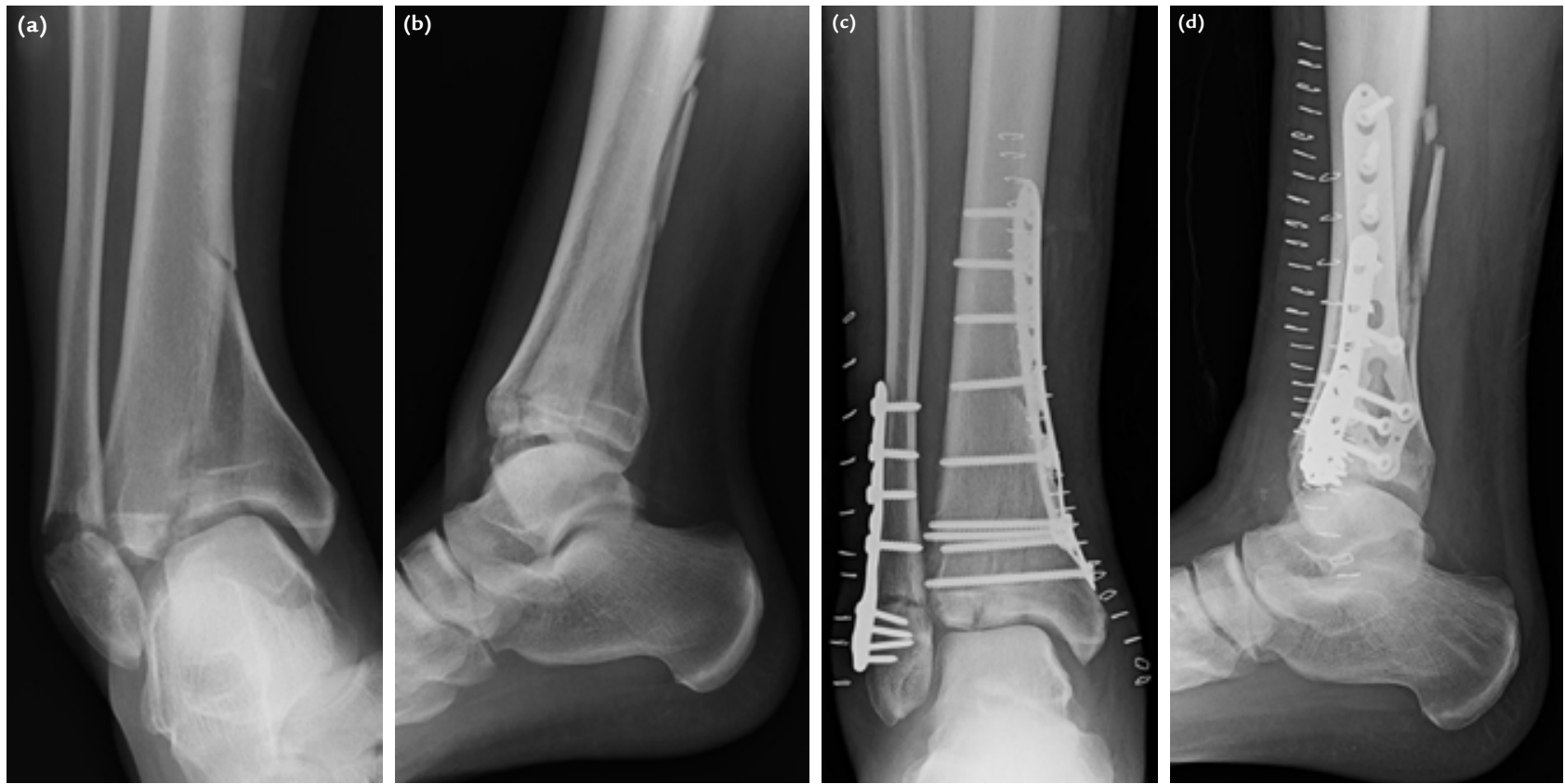

Şekil 5. a-d. Varus deformasyonu gösteren deplase tibia ve fibula pilon kırığının ön-arka (a) ve lateral (b) grafileri. Açık redüksiyon, plak ve vidalar ile tespit sonrası ön-arka (c) ve lateral (d) grafiler.

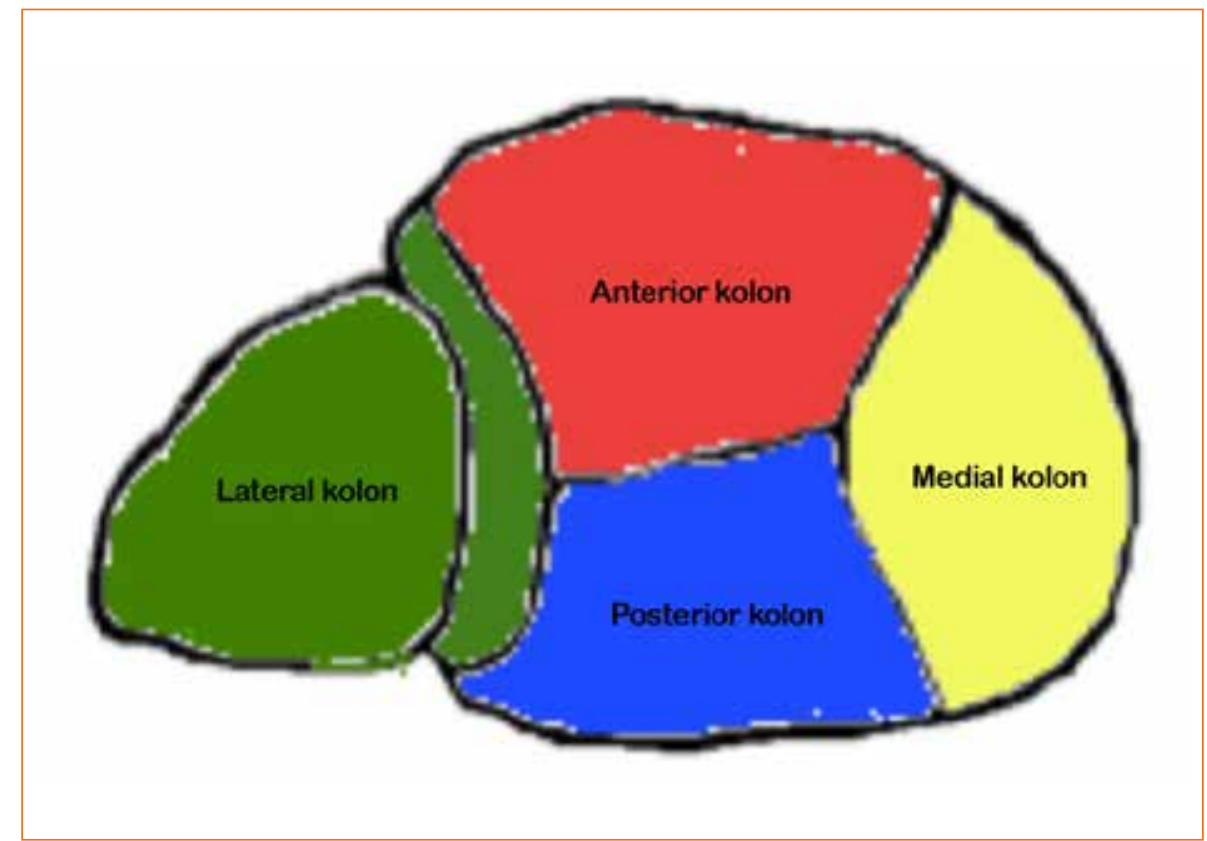

Şekil 6. Dört kolon sınıflamasının şematik çizimi.

Yakın zamanda tanımlanmış dört kolon sınıflamasında ise, distal tibia ve fibula anatomik özelliklerine göre dört kolona ayrılmıştır. Anterior ve posterior kolon, medial ve lateral malleolü birleştiren intermalleolar bir çizgi ile, medial ve lateral kolonlar ise sagittal orta hat çizgisi ile ayrılmıştır (Şekil 6). Bu sınıflamanın tedavi seçimine yol gösterdiği bildirilmiş; kırık fragmanlarının bulundukları kolona göre tespiti önerilmiştir. Özetle; anterior kolonu ilgilendiren kırıklara anterior, posterior kolonu ilgilendirenlere posterior, medial kolonu ilgilendirenlere medial tespit ve lateral kolonu ilgilendiren kırıklara ise lateral distal tibia, fibula, tibiofibular sindezmoz tespiti önerilmiştir. ${ }^{[12]}$ 


\section{KAYNAKLAR}

1. Helfet DL, Koval K, Pappas J, Sanders RW, DiPasquale T. Intraarticular "pilon" fracture of the tibia. Clin Orthop Relat Res 1994;(298):221-8.

2. Dujardin F, Abdulmutalib H, Tobenas AC. Total fractures of the tibial pilon. Orthop Traumatol Surg Res 2014;100(1 Suppl):S65-74. Crossref

3. Borrelli J Jr, Ellis E. Pilon fractures: assessment and treatment. Orthop Clin North Am 2002;33(1):231-45.

4. Jacob N, Amin A, Giotakis N, Narayan B, Nayagam S, Trompeter AJ. Management of high-energy tibial pilon fractures. Strategies Trauma Limb Reconstr 2015;10(3):137-47. Crossref

5. Tornetta P 3rd, Gorup J. Axial computed tomography of pilon fractures. Clin Orthop Relat Res 1996;(323):273-6.

6. Rüedi TP, Allgöwer M. The operative treatment of intraarticular fractures of the lower end of the tibia. Clin Orthop Relat Res 1979;(138):105-10.

7. Marsh JL, Slongo TF, Agel J, Broderick JS, Creevey W, DeCoster TA, Prokuski L, Sirkin MS, Ziran B, Henley B, Audigé L. Fracture and dislocation classification compendium - 2007: Orthopaedic Trauma Association classification, database and outcomes committee. J Orthop Trauma 2007;21(10 Suppl):S1-133.
8. Martin JS, Marsh JL, Bonar SK, DeCoster TA, Found $E M$, Brandser EA. Assessment of the AO/ASIF fracture classification for the distal tibia. J Orthop Trauma 1997;11(7):477-83.

9. Swiontkowski MF, Sands AK, Agel J, Diab M, Schwappach $J R$, Kreder HJ. Interobserver variation in the AO/OTA fracture classification system for pilon fractures: is there a problem? J Orthop Trauma 1997;11(7):467-70.

10. Stapleton JJ, Zgonis T. Surgical treatment of tibial plafond fractures. Clin Podiatr Med Surg 2014;31(4):547-64. Crossref

11. Topliss CJ, Jackson M, Atkins RM. Anatomy of pilon fractures of the distal tibia. J Bone Joint Surg $\mathrm{Br}$ 2005;87(5):692-7.

12. Tang $X$, Tang PF, Wang MY, Lü DC, Liu MZ, Liu CJ, Liu Y, Sun LZ, Huang LJ, Yu L, Zhao YG. Pilon fractures: A new classification and therapeutic strategies. Chin Med J (Engl) 2012;125(14):2487-92. 